\title{
Application of a Disaggregation Method for the Generation of Climate Changed Intensity-Duration-Frequency Curves for Predicting Future Extreme Rainfall Impacts on Transportation Infrastructure
}

\author{
Cesar Do Lago ${ }^{1, *}$, Eduardo Mendiondo ${ }^{2}$,Francisco Olivera $^{3}$, and Marcio Giocomoni ${ }^{2}$ \\ ${ }^{1}$ Department of Civil and Environmental Engineering, University of Texas at San Antonio, San Antonio, TX 78248-0670 \\ ${ }^{2}$ Department of Hydraulic and Sanitation, University of Sao Paulo, Sao Carlos, SP, Brazil, 13560-649 \\ ${ }^{3}$ Zachry Department of Civil Engineering, Texas A\&M University, College Station, TX 77843-3136
}

\begin{abstract}
Potential consequences of climate change are the increase in the magnitude and frequency of extreme rainfall storm events. In order to assess what are the potential impacts of climate change in the transportation infrastructure, new intensity-duration-frequency curves are needed. In this study, projected IDF curves were created based on three Global Climate Models (GCM) for the representative concentration pathways (RCP) 4.5 and 8.5. The selected GCMs are: ACCESS1-0, CSIRO-MK3-0-6 and GFDL-ESM2M. Projected IDFs for the near (2025-2049), mid (2050-2074) and far future (2075-2099) were created after disaggregating the project rainfall time series using the Bartlett-Lewis Rectangular Pulses Stochastic Model. The projected IDFs were compared with the IDF currently used and generated based on historical data. The results indicate that climate change is likely to decrease rainfall intensities in all the future horizons in the tested area of San Antonio, Texas. Further analysis is recommended, including the use of bias correction of those GCM models and use of a broader range of models that can better quantify uncertainty of the future rainfall regime.
\end{abstract}

\section{Introduction}

One of potential impacts of climate change is the increase in the frequency and intensity of flooding caused by rainfall events [1]. Associated with the negative impacts of population growth and urbanization, which increases surface runoff due to the increase in imperviousness, the impacts on the economy and number of fatalities caused by climate change induced flooding in the future are expected to rise. Data from the National Center for Environmental Information (NCEI), which is the agency within the National Oceanic and Atmospheric Administration (NOAA) responsible for scorekeeping these impacts, show a significant increase in the total costs associated with extreme events since 1980s. Recently, the United States registered the occurrence of a number of extreme storm events, including: Hurricane Harvey in 2017 as a 1,000-year storm [18]; Baton Rouge flooding, in 2016, as a consequence of a 500-year storm [2]; and superstorm Sandy in 2012 with a return period between 150 to 1,000 years [3]. According to NOAA [4], the United States has experienced 16 major flood events in the past 10 years that exceeded $\$ 1$ billion in losses, totalizing adjusted to $\$ 51.2$ billion in economic damages; these flood events also resulted in 224 deaths. Besides casualties and economic losses, floods can affect public health by spreading disease $[5,6]$ and causing psychological disorders among the population, such as post-traumatic stress disorder, anxiety, sleep disorder and depression $[7,8]$.

Most critical infrastructure built in urban areas in the U.S., including that for transportation and flood protection, are designed to handle design storms with a $1 \%$ probability of occurrence in one year or 100 years of return period. A design storm is a fictitious hyetograph characterized by a total duration and a rain depth or intensity for a particular return period [9]. Design storms are created based on intensity-duration-frequency (IDF) curves that are built for a particular location (e.g. county, city or rain gauge) based on high temporal resolution historical rainfall records. They are used in conjunction to hydrologic and hydraulic models to estimate flood characteristics (e.g. peak flows or water depths) in a watershed. Because climate change is likely to alter the IDF relationships, the prediction of future flood events requires methods that can incorporate the impacts of climate change on future IDF curves.

Climate change projections have been produced in the past decades by many climate research groups around the world. These projections are generated using Global Climate Models (GCMs) which are numerical simulation models used to represent a climate system based on physical, chemical and biological processes in the atmosphere, ocean, cryosphere and land surface [10].

\footnotetext{
* Corresponding author: cesar-lago@hotmail.com
} 
Most GCMs generate rainfall and other climate variables in a daily time scale from 1900 to 2100 , aiming to represent historical climate and generate future projections in many locations around the world. Because IDF relationships require high resolution temporal rainfall time series, the use of GCMs for creating climate changed updated IDF relationships require the use of a rainfall disaggregation method. In the present article, a Modified Bartlett-Lewis Rectangular Pulses Stochastic model [11] is used to generate high resolution temporal rainfall time series from several GCMs rainfall time series. The downscaled rainfall time series are then used to create IDF curves. A comparison with the existing IDF curves for the City of San Antonio is performed.

\section{Methodology}

The methodology used in this article follows three main steps. First, GCM rainfall data was acquired. Second, the future rainfall projections were disaggregated into a finer temporal resolution. Finally, the disaggregated rainfall series were used to generate the IDF curves.

The climate change scenarios were acquired from the World Climate Research Programme's (WCRP's) coupled model intercomparison project phase 5 (CMIP5) [12]. Three main GCM model outputs for the most probable emission scenario (RCP 4.5) and the most pessimist scenario (RCP 8.5) were selected: ACCESS10, CSIRO-MK3-0-6 and GFDL-ESM2M. These model outputs were available from the Bias-Correction and Constructed Analogs version 2 (BCCAv2) downscale method for climate changes data, which already has biascorrection. These GCMs were selected based on their performance in predicting extreme rainfall indexes: $95^{\text {th }}$ and $99^{\text {th }}$ rainfall percentiles, maximum daily and 5 days rainfall depths and number of days over 10 and $20 \mathrm{~mm}$ [19]. The daily rainfall time series were divided into three periods: near future (2025 to 2049), medium future (2050 to 2074) and far future (2075 to 2100).

The disaggregation of GCM precipitation was performed using the Modified Bartlett-Lewis Rectangular Pulses Stochastic model [11] with adjusting procedures, according to the methodology proposed by Kossieris et al., [13]. Autocorrelation, proportion of dry days, variance and rainfall mean depth were the indices used to estimate the model parameters. The Generalized Reduced Gradient algorithm [14] was applied to reduce the Square Mean Errors between the simulated and observed values of such indices to estimate the parameters $\lambda, \alpha, v, \kappa, \varphi$ and $\mu_{x}$. A rainfall series with 15 minutes time resolution, registered from 1999 to 2014, were used to calibrate these parameters (Station ID: COOP:417947). Finally, the parameters of Sherman's IDF [15] relationships, given by equation 1, for the future scenarios were obtained. To estimate those, the year maximum rainfall depth was obtained for intervals of $15 \mathrm{~min}, 30 \mathrm{~min}, 1 \mathrm{hr}, 3 \mathrm{hr}, 6 \mathrm{hr}, 12 \mathrm{hr}$, 1 day, 3 days, 7 days and 14 days, and subsequently converted to intensities. Then, a Gumbel distribution was applied to calculate the intensities for different return periods: 2, 5, $10,25,50$ and 100 years. The Nelder-Mead heuristic optimization algorithm [16] was used to estimate the parameters $e, b$ and $d$ to best the results from equation 1 with the estimated intensities.

$$
i_{R}=\frac{e}{(t+d)^{b}}
$$

where $i$ is the rainfall intensity, $d$ is the duration and $R$ the return period. The comparison was made with the parameters by Cleveland et al., [17], from Texas Department of Transportation (TxDOT). Extreme rainfalls from hurricanes cause the greatest damages and usually last between 12 and 24 hours, which are the target of this study. Therefore, the total depth for those durations were quantified to evaluate the potential impact of climate changes on extreme events.

\section{Results and discussion}

Figure 1 presents the estimated IDF curves for the 100 years return period for historical rainfall series (TxDOT), and the three GCMs for both the scenarios RCP 4.5 and RCP 8.5 for the near $(2025$ - 2049), medium (2050 2074) and far future (2075-2099). The intensities of the historic IDF are generally higher than those generated by IDFs from GCMs, except for the short rainfall duration ( $<6$ hours) projected by GFDL-ESM2M RCP 8.5 in the near and far future. The divergence between scenarios and the historical IDF is more visible for longer rainfall durations. All three GCM, under both scenarios, points to lower rainfall intensities in the future for higher durations. The result of lower intensities for most durations is less total rainfall depth, as shown in Figure 2, which presents the 100 years 12 and $24 \mathrm{hrs}$ total rainfall depth. For instance, according to the TxDOT IDF, the 100 years $24 \mathrm{hrs}$ storm event amounts to approximately $254 \mathrm{~mm}$. All projected GCMs indicate reductions that range from approximately 219 to 129 $\mathrm{mm}$, which represent 19 to $49 \%$ in the total rainfall depth.

This finding is counterintuitive to what has been suggested by the literature that claims climate change will increase the intensity and frequency of intense storm events. Analysis in the raw daily rainfall depth from the all GCM and both RCP scenarios show, however, that San Antonio is likely to have substantial reduction in the overall rainfall regime. For instance, the maximum total daily depth of $180.4 \mathrm{~mm} /$ day was registered by CSIROMK3-1-0 under RCP8.5 in the far future. This value is significantly lower when compared to the $286 \mathrm{~mm}$ /day registered at the COOP 417947 station in 1988. 


\section{RCP 4.5}
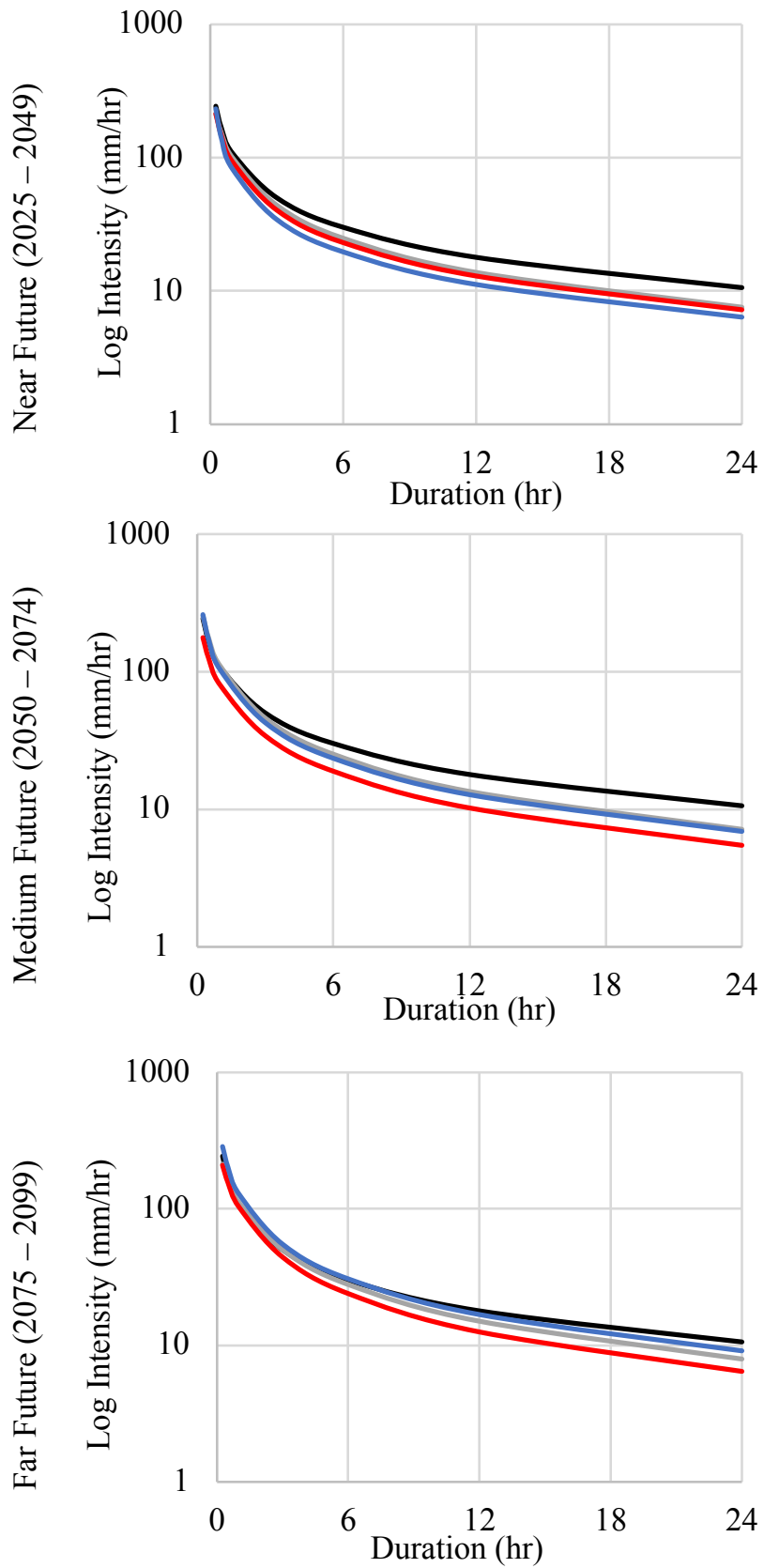

RCP 8.5
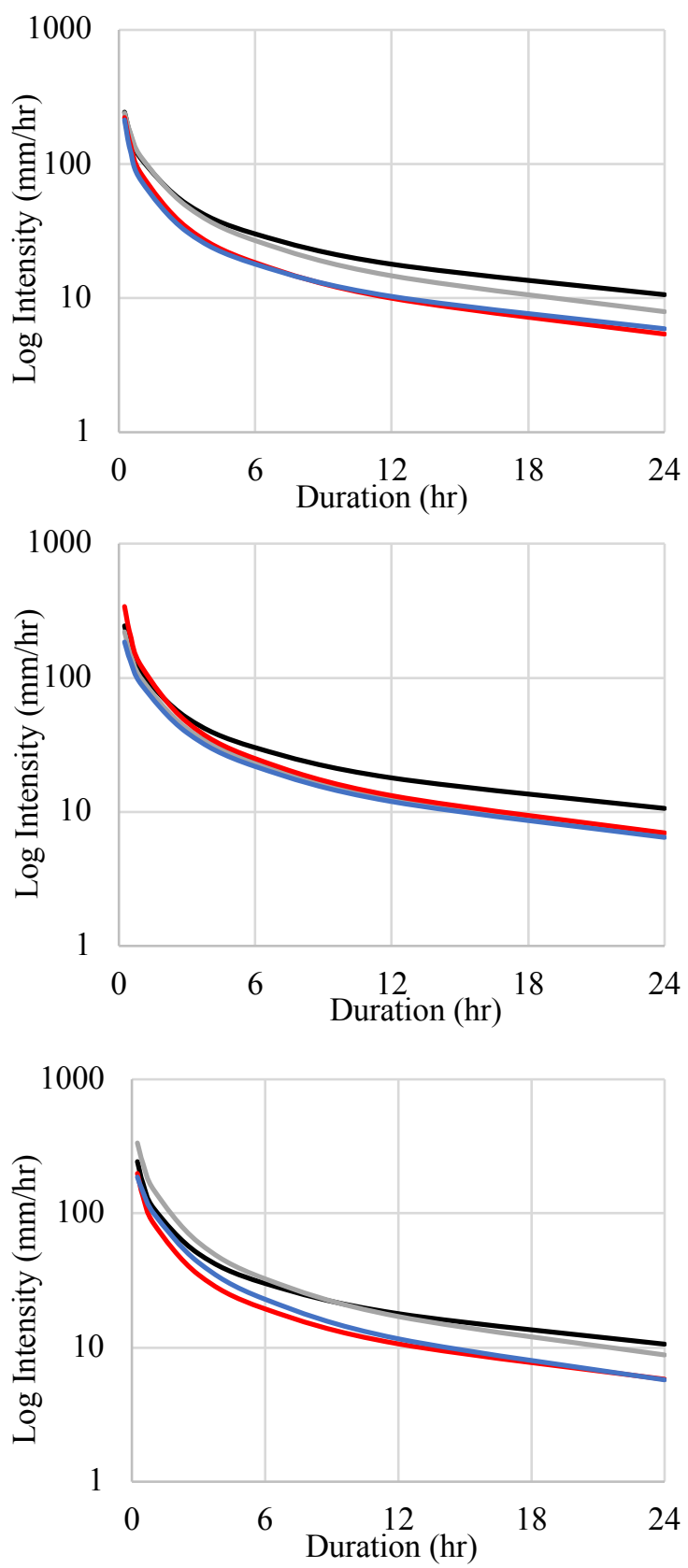

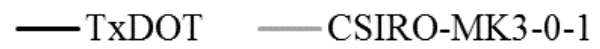

-GFDL-ESM2M

ACCESS1-0

Fig. 1. TxDOT, CSIRO-MK3-0-1, GFDL-ESM2M and ACCESS1-0 IDF curves for 100 year of return period for the RCP $4.5 \& 8.5$.

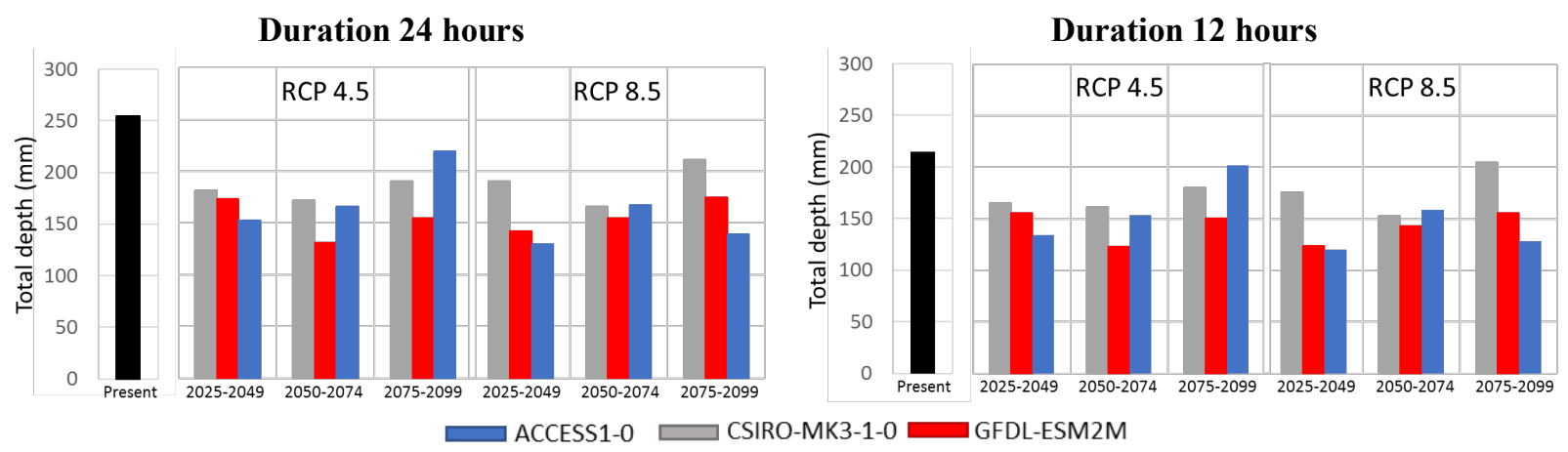

Fig. 2. Total depth for the 12 and 24 hours for the 100 year of return period. 


\section{Conclusions}

The present article evaluated the potential impact of climate change in the IDF relationships in San Antonio, TX. Three climate change GCM models and two RCP scenarios daily rainfall projections were disaggregated to generated updated IDFs. All the scenarios indicate reductions in the rainfall intensities for all durations and return periods, which led to significant reductions in the overall total rainfall depth. The results indicate that uncertainties of the GCMs can be propagated to updated IDF curves. Kundzewicz et al. [20] discusses two managing methods for uncertainties under climate changes. The first is by precaution, which consider the worst scenario for the mitigation plans. The second is the multi-model probabilistic approach, which may present different solutions based on the different results presented by various global models. Future work is required to better understand the sources of uncertainties brought by GCM projects and whether the adjustments of IDF parameters enhance the uncertainties of projected design storm events. Further bias treatment on those GCM model outputs are required to prevent underestimation of the potential extreme rainfalls.

\section{References}

1. Milly, P., Betancourt, J., Falkenmark, M., Hirsch, R., Kundzewicz, Z., Lettenmaier, D., and Stouffer, R. (2008). Climate change - Stationarity is dead: Whither water management?. Science, 319(5863), 573-574.

2. Wiel, K.V.D., Kapnick, S.B., Oldenborgh, G.J.V., Whan, K., Philip, S., Vecchi, G.A., and Cullen, H. (2017). Rapid attribution of the August 2016 floodinducing extreme precipitation in south Louisiana to climate change. Hydrology and Earth System Sciences, 21(2), 897-921.

3. Karamouz, M., Razmi, A., Nazif, S., and Zahmatkesh, Z. (2017). Integration of inland and coastal storms for flood hazard assessment using a distributed hydrologic model. Environmental Earth Sciences, 76(11), 395.

4. NOAA National Centers for Environmental Information (NCEI). (2018). U.S. Billion-Dollar Weather and Climate Disasters https://www.ncdc.noaa.gov/billions/. Accessed < October 3, 2018>

5. Liu, Z., Lao, J., Zhang, Y., Liu, Y., Zhang, J., Wang, H., and Jiang, B. (2018). Association between floods and typhoid fever in Yongzhou, China: effects and vulnerable groups. Environmental research, 167, 718-724.

6. Wijerathne, K.B.P.C.A., and Senevirathna, E.M.T.K. (2018). Identify the risk for leptospirosis disease during flooding periods (Special reference to Medirigiriya Divisional Secretariat Division in Polonnaruwa district). Procedia engineering, 212, 101-108.

7. Munro, A., Kovats, R.S., Rubin, G.J., Waite, T.D., Bone, A., Armstrong, B., and Oliver, I. (2017).
Effect of evacuation and displacement on the association between flooding and mental health outcomes: a cross-sectional analysis of UK survey data. The Lancet Planetary Health, 1(4), e134-e141.

8. Zhong, S., Yang, L., Toloo, S., Wang, Z., Tong, S., Sun, X., and Huang, C. (2018). The long-term physical and psychological health impacts of flooding: A systematic mapping. Science of the Total Environment, 626, 165-194.

9. McCuen, R.H. (2004). Hydrologic analysis and design (3rd ed). Pearson Education Inc, Upper Saddle River, NJ.

10. IPCC, 2013: Annex III: Glossary [Planton, S. (ed.)]. In: Climate Change 2013: The Physical Science Basis. Contribution of Working Group I to the Fifth Assessment Report of the Intergovernmental Panel on Climate Change [Stocker, T.F., D. Qin, G.-K. Plattner, M. Tignor, S.K. Allen, J. Boschung, A. Nauels, Y. Xia, V. Bex and P.M. Midgley (eds.)]. Cambridge University Press, Cambridge, United Kingdom and New York, NY, USA.

11. Rodriguez-Iturbe, Cox, D.R., and Isham, V. (1988). A point process model for rainfall: further developments. Proc. R. Soc. Lond. A, 417(1853), 283-298.

12. Brekke, L., Thrasher, B. L., Maurer, E. P., \& Pruitt, T. (2013). Downscaled CMIP3 and CMIP5 climate projections: release of downscaled CMIP5 climate projections, comparison with preceding information, and summary of user needs. US Department of the Interior, Bureau of Reclamation, Technical Service Center, Denver, Colorado, 116.

13. Kossieris, P., Makropoulos, C., Onof, C., and Koutsoyiannis, D. (2016). A rainfall disaggregation scheme for sub-hourly time scales: Coupling a Bartlett-Lewis based model with adjusting procedures. Journal of Hydrology, 556, 980-992.

14. Abadie, J., and Carpentier, J. (1992). Generalization of the Wolfe Reduced Gradient Method to the Case of Nonlinear Constraints. Optimization, R. Fletcher, ed., Academic Press, 1969, p. 37. American Society of Civil Engineers (ASCE) and the Water Environment Federation (WEF), 1992. Design and Construction of Urban Stormwater Management Systems. ASCE Manuals and Reports of Engineering Practice No. 77, WEF Manual of Practice FD-20

15. Sherman, C. (1931). Frequency and intensity of excessive rainfall at Boston, Massachusetts, Transactions, American Society of Civil Engineers, 95, 951-960.

16. Nelder, J.A., and Mead, R. (1965). A simplex method for function minimization. Computer Journal. 7: 308-313. doi:10.1093/comjnl/7.4.308.

17. Cleveland, T.G., Herrmann, G.R., Tay, C.C., Neale, C.M., Schwarz, M.R., and Asquith, W.H. (2015). New Rainfall Coefficients-Including Tools for Estimation of Intensity and Hyetographs in Texas (No. FHWA/TX-15/0-6824-1).

18. van Oldenborgh, G.J., van der Wiel, K., Sebastian, A., Singh, R., Arrighi, J., Otto, F., ... \& Cullen, H. (2017). Attribution of extreme rainfall from 
Hurricane Harvey, August 2017. Environmental Research Letters, 12(12), 124009.

19. Sillmann, J., Kharin, V.V., Zhang, X., Zwiers, F.W., \& Bronaugh, D. (2013). Climate extremes indices in the CMIP5 multimodel ensemble: Part 1. Model evaluation in the present climate. Journal of Geophysical Research: Atmospheres, 118(4), 17161733.

20. Kundzewicz, Z.W., Krysanova, V., Benestad, R.E., Hov, Ø., Piniewski, M., \& Otto, I.M. (2018). Uncertainty in climate change impacts on water resources. Environmental Science \& Policy, 79, 1-8 